\title{
Dopamine, Effort-Based Choice, and Behavioral Economics: Basic and Translational Research
}

\author{
John D. Salamone ${ }^{1 *}$, Merce Correa ${ }^{1,2}$, Jen-Hau Yang ${ }^{1}$, Renee Rotolo ${ }^{1}$ and Rose Presby ${ }^{1}$ \\ ${ }^{1}$ Department of Psychological Sciences, University of Connecticut, Storrs, CT, United States, ${ }^{2}$ Area de Psicobiologia, \\ Universitat de Jaume I, Castelló, Spain
}

Operant behavior is not only regulated by factors related to the quality or quantity of reinforcement, but also by the work requirements inherent in performing instrumental actions. Moreover, organisms often make effort-related decisions involving economic choices such as cost/benefit analyses. Effort-based decision making is studied using behavioral procedures that offer choices between high-effort options leading to relatively preferred reinforcers vs. low effort/low reward choices. Several neural systems, including the mesolimbic dopamine (DA) system and other brain circuits, are involved in regulating effort-related aspects of motivation. Considerable evidence indicates that mesolimbic DA transmission exerts a bi-directional control over exertion of effort on instrumental behavior tasks. Interference with DA transmission produces a low-effort bias in animals tested on effort-based choice tasks, while increasing DA transmission with drugs such as DA transport blockers tends to enhance selection of high-effort options. The results from these pharmacology studies are corroborated by the findings from recent articles

OPEN ACCESS

Edited by:

Paul E. M. Phillips,

University of Washington,

United States

Reviewed by:

Caroline E. Bass,

University at Buffalo, United States Alicia Izquierdo,

University of California, Los Angeles, United States

${ }^{*}$ Correspondence: John D. Salamone john.salamone@uconn.edu

Received: 12 December 2017 Accepted: 28 February 2018 Published: 23 March 2018

Citation: Salamone JD, Correa $M$, Yang $J-H$, Rotolo $R$ and Presby $R$ (2018) Dopamine, Effort-Based Choice, and Behavioral Economics: Basic and Translational Research.

Front. Behav. Neurosci. 12:52. doi: 10.3389/fnbeh.2018.00052 using optogenetic, chemogenetic and physiological techniques. In addition to providing important information about the neural regulation of motivated behavior, effort-based choice tasks are useful for developing animal models of some of the motivational symptoms that are seen in people with various psychiatric and neurological disorders (e.g., depression, schizophrenia, Parkinson's disease). Studies of effort-based decision making may ultimately contribute to the development of novel drug treatments for motivational dysfunction.

Keywords: motivation, reward, ventral striatum, accumbens, effort-related decision making, models, depression

\section{BEHAVIORAL ECONOMICS, CHOICE AND THE NEURAL REGULATION OF MOTIVATED BEHAVIOR}

It is something of a truism that the field of economics is not about money, but rather, it is about choice. As it turns out, much of the study of motivation is also about understanding the neural basis of choice, which ultimately means that economic concepts and approaches can enlighten and inform research on the neurobiology of motivation (Salamone et al., 2016a,c, 2017). There is a rich literature on behavioral economics that has emerged from the field of experimental behavior analysis (e.g., Hursh and Winger, 1995; Bickel et al., 2000; Madden et al., 2000, 2007), which has provided useful terms and methods that can aid neuroscientists. For example, the results of some instrumental behavioral experiments, including those focusing on drug reinforcers, can be analyzed by quantative economic methods such as 
demand curves (Hursh and Winger, 1995; Heyman, 2000; Salamone et al., 2009; Madden and Kalman, 2010; Heinz et al., 2012; Bentzley et al., 2013, 2014; Bentzley and Aston-Jones, 2015).

According to the classical view of the reinforcement of instrumental behavior, a reinforcer is a stimulus that strengthens a response. Thus, a positive reinforcer is a stimulus that, when presented after a response, increases the probability or frequency of that response (Skinner, 1953). However, there are additional views of reinforcement that also are necessary to understand in order to explicate the deeper significance of this process. Positive reinforcers are typically motivational stimuli that the organism is likely to approach, or seeking to attain, and which would tend to occur with a relatively high probability in an unconstrained environment (Thorndike, 1911; Premack, 1959; Salamone and Correa, 2002). Furthermore, viewed from the perspective of economics, a reinforcer is a good or commodity, or an object or activity that has relatively high value. Given this background, what is an instrumental behavior such as pressing a lever, running in a maze, or pressing a computer keyboard? According to economic principles, an instrumental behavior is the labor that is exchanged for the good or commodity (i.e., the reinforcer). Thus, positively reinforced behavior is essentially a barter system, in which the organism trades its work for access to the reinforcer (Rachlin, 2003; Salamone et al., 2009). It therefore appears that instrumental response requirements are the price (i.e., the response cost) that needs to be paid in order to obtain access to motivationally relevant stimuli that are serving as reinforcers.

There is no shortage of articles in behavioral neuroscience that focus on "reward" or "reward value" or "outcome valuation". The dopamine (DA) hypothesis of "reward" has been a ubiquitous feature of psychopharmacology and behavioral neuroscience for decades (e.g., but see also Salamone et al., 2007 and Nicola, 2016 for problems with this hypothesis). Decision making studies in animal subjects and human participants that investigate the impact of reinforcers differing in quality or quantity, or factors such as reinforcement delay or probability, have contributed greatly to our understanding of the neural regulation of motivated behavior (Floresco, 2015; Wassum and Izquierdo, 2015; Winstanley and Floresco, 2016). Nevertheless, it can be argued that the study of the other side of the equation, the labor or cost side, is equally important (Salamone and Correa, 2012; Wassum and Izquierdo, 2015; Salamone et al., 2016a,c; Winstanley and Floresco, 2016). To this end, several laboratories including our own have been focusing on the neural regulation of choice based upon exertion of physical effort. The work performed in order to obtain access to reinforcing stimuli is itself an important factor in regulating instrumental behavior, one which should not be subsumed or hidden under the general umbrella of "reward value", but rather should receive its own spotlight. It is not as though the brain merely functions to assess the value of stimuli, and the actions necessary to obtain those stimuli are just some epiphenomena. It trivializes the neural regulation of instrumental behaviors to consider them merely as a small part of the "rewarding outcome", when in fact they are the actions that lead to the outcome. Importantly, there is considerable evidence that manipulations affecting brain functions, such as drugs or lesions, can dissociate the exertion of effort in instrumental behavior from reinforcement value based upon preference (Salamone et al., 2016a,c, 2017). The present review will discuss some of this research, with a particular focus on the role of forebrain circuits and neurotransmitters such as DA, adenosine and GABA. Furthermore, this review will briefly describe how research on effort-based choice behavior can lead to the development of animal models that are useful for understanding aspects of psychopathology.

\section{EFFORT-RELATED CHOICE AND NUCLEUS ACCUMBENS DA}

\section{Conceptual Background}

The processes involved in initiating and sustaining instrumental actions, including the exertion of effort needed to overcome obstacles and obtain access to motivationally relevant stimuli, are necessary for survival. However, a complex environment can involve potential access to several different reinforcers, and distinct paths for accessing them. For these reasons, organisms must make choices involving several factors, including cost/benefit assessments based upon work requirements and reinforcement preference (Salamone and Correa, 2002, 2012; Walton et al., 2006; Salamone et al., 2007, 2016a,b,c; Winstanley and Floresco, 2016). Considerable evidence indicates that nucleus accumbens DA, along with other transmitters and structures, participates in the neural circuitry that regulates effort-based choice behavior (Salamone et al., 2007, 2009, 2016a,b,c; Floresco et al., 2008a; Hauber and Sommer, 2009; Mai et al., 2012; Floresco, 2015; Winstanley and Floresco, 2016). The effects of interfering with DA transmission have been assessed in many ways (Salamone et al., 2016a,b,c), including systemic or intracranial injections of DA antagonists, local depletions of accumbens DA with injections of the neurotoxic agent 6-hydroxydopamine (6-OHDA), or systemic administration of the DA depleting agent tetrabenazine, which blocks vesicular storage by inhibiting the type- 2 vesicular monoamine transporter (VMAT-2). Moreover, various pharmacological, genetic, and optogenetic methods have been used to determine the effects of augmenting DA transmission.

\section{T-Maze Choice Procedures}

One of the procedures that has been used to assess the contribution of accumbens DA to response allocation and effortrelated choice behavior is a T-maze barrier choice procedure developed by Salamone et al. (1994). With this procedure, the two choice arms of the maze can have different reinforcement densities (e.g., 4 vs. 2 food pellets, or 4 vs. 0), and under some conditions a vertical barrier is placed in the arm with the higher density of food reinforcement to present an effortrelated challenge. Under conditions in which the high-density arm ( 4 pellets) had the barrier in position, and the arm without the barrier contained an alternative food source ( 2 pellets), DA depletions or antagonism substantially alter effort-based choice, 
decreasing selection of the high-density arm, while increasing choice of the low-density arm with no barrier (Salamone et al., 1994; Cousins et al., 1996; Denk et al., 2005; Mott et al., 2009; Yohn et al., 2015a,b). The T-maze barrier choice task has undergone considerable behavioral validation and evaluation (Salamone et al., 1994; Cousins et al., 1996; van den Bos et al., 2006; Ostrander et al., 2011; Pardo et al., 2012; Yohn et al., 2015a,b). If there is no barrier obstructing the arm with the high reinforcement density, rats mostly choose that arm, and neither D1 or D2 family antagonists, nor accumbens DA depletions, nor tetrabenazine alter arm choice (Salamone et al., 1994; Yohn et al., 2015a,b). When the arm with the barrier contains 4 pellets, but the other arm contains no pellets, and thus the only way to obtain food is to climb the barrier, rats with DA depletions still choose the high-density arm, climb the barrier, and eat the pellets (Cousins et al., 1996; Yohn et al., 2015a). In a mouse study, although the DA antagonist haloperidol produced a low-effort bias when the high reward arm had a barrier, it had no effect on choice when both arms had a barrier in place (Pardo et al., 2012). Thus, interference with DA transmission did not alter preference for the high density of food reward over the low density, did not affect discrimination or reference memory processes related to arm preference, and did not produce an absolute impairment in the ability to climb the barrier.

\section{Lever Pressing Choice Procedures}

Another commonly used task for assessing effort-based choice is the concurrent lever pressing/chow feeding procedure. With this task, rats are offered the option of either lever pressing to obtain a relatively preferred food (e.g., Bio-serv pellets; usually obtained on a fixed ratio 5 (FR5) schedule), or approaching and consuming a less preferred food (lab chow) that is concurrently available in the chamber. Well trained rats under baseline conditions typically get most of their food by lever pressing, and consume only small quantities of chow (Salamone et al., 1991, 2002). Low-to-moderate doses of DA D1 or D2 receptor antagonists produce a substantial shift in response allocation in rats performing on this task, decreasing lever pressing for food but substantially increasing intake of the concurrently available chow (Salamone et al., 1991, 2002; Cousins et al., 1994; Sink et al., 2008; Worden et al., 2009). This low-effort bias is also induced by local intra-accumbens injections of DA antagonists, neurotoxic depletions of accumbens DA, and tetrabenazine (Salamone et al., 1991; Cousins et al., 1993; Koch et al., 2000; Nowend et al., 2001; Farrar et al., 2010; Nunes et al., 2013a). As with the T-maze task, the use of the concurrent FR5/chow feeding choice task for assessing effort-related choice behavior has been validated in many ways. For example, the low doses of DA antagonists or tetrabenazine that produce the low-effort bias in effortbased choice did not affect total food intake or alter preference between these two specific foods in free-feeding choice tests (Salamone et al., 1991; Nunes et al., 2013a). The effects of DA antagonism or depletion were not mimicked by appetite suppressants belonging to several different classes, including amphetamine (Cousins et al., 1994), fenfluramine (Salamone et al., 2002) and cannabinoid CB1 antagonists (Sink et al., 2008), which failed to increase chow intake at doses that suppressed lever pressing, and in fact tended to decrease chow intake. In addition, reinforcer devaluation by pre-feeding to reduce food motivation suppressed both lever pressing and chow intake (Salamone et al., 1991). In more recent series of experiments, rats were given a choice between lever pressing on a FR7 schedule for a high concentration of sucrose vs. approaching and consuming a less preferred lower concentration (Pardo et al., 2015). In that study, tetrabenazine shifted choice behavior, decreasing lever pressing but substantially increasing intake of the lower concentration of sucrose that was concurrently available. These effects of tetrabenazine were seen at doses that did not alter preference between the two sucrose solutions, and did not blunt the appetitive taste reactivity (sometimes referred to as hedonic reactivity) induced by sucrose (Pardo et al., 2015). Taken together, these findings demonstrate that interference with DA transmission under conditions that suppress instrumental actions does not simply reduce appetite or primary food motivation. Rather, these manipulations alter the allocation of instrumental responses in a manner that interacts with the response requirement rather than the particular quality or quantity of the food reinforcer. Thus, rodents with compromised DA transmission still maintain fundamental aspects of food motivation, and are still directed towards the acquisition and consumption of food, but they have a low-effort bias and select an alternative, less effortful path to obtain food.

\section{EFFORT DISCOUNTING AND PROGRESSIVE RATIO/CHOW FEEDING CHOICE PROCEDURES OFFER INSIGHTS INTO THE EFFORT-RELATED MOTIVATIONAL FUNCTIONS OF DA}

\section{Effort Discounting Procedures}

In addition to the behavioral tasks described above, several other procedures have been developed in order to assess effort-related motivational processes. Bardgett et al. (2009) developed an effort discounting task based upon the T-maze barrier procedures, and reported that D1 and D2 antagonism produced a low-effort bias. Floresco et al. (2008b) studied the effects of the DA antagonist flupenthixol using a discrete trial ratio discounting procedure in which rats could either emit a single press to receive two pellets (low-reward lever), or emit 2, 5, 10 or 20 responses to obtain four pellets (high effort/high-reward lever). Flupenthixol shifted effort discounting, reducing selection of the high effort lever in a manner that was independent of any effects of delay of reinforcement. In subsequent studies using this procedure it was shown that the effects of DA D1 or D2 receptor antagonism were characterized by actions on discounting based upon physical effort (ratio discounting) but not cognitive effort discounting (Hosking et al., 2015). To the extent that waiting for a reward involves some type of cognitive effort, it is interesting to note that local injections of DA antagonists into nucleus accumbens did not affect progressive interval responding (Wakabayashi et al., 2004). Robles and Johnson (2017) found that intraventricular injection of the D2 antagonist eticlopride altered effort-based decision making as assessed using a mouse two-lever choice task. 


\section{Progressive Ratio Choice Procedures}

Another procedure for assessing effort-based choice is a variant of the lever pressing/chow feeding task, which employs a progressive ratio (PROG) schedule as the lever pressing component. In order to understand this task, it is useful to provide some background on PROG operant schedules. With PROG schedules, the ratio requirement increases as successive ratios are completed, and responding continues until a "break point" occurs, at which point the animal essentially ceases to respond for a period of time. Determination of PROG break points can be a very useful tool for characterizing some of the actions of drugs that are self-administered, and for comparing self-administration behavior across different drugs or drug classes (e.g., Marinelli et al., 1998; Woolverton and Ranaldi, 2002). However, attaching conceptual or theoretical significance to the results of studies involving PROG schedules can be somewhat complicated. Although it is sometimes common to see PROG break points used as a measure of "reward", it should be emphasized that break points do not actually provide a simple measure of the quality or quantity of a reinforcing stimulus in a manner that is uncontaminated by other factors (Salamone et al., 2009). In fact, drug or lesion-induced changes in PROG break points can reflect much more than effects on the appetitive motivational properties of a reinforcing stimulus (Arnold and Roberts, 1997; Hamill et al., 1999). For example, responserelated factors such as changing the kinetic requirements of the instrumental response (e.g., increasing the height of the lever) was shown to decrease progressive ratio break points (Skjoldager et al., 1993; Schmelzeis and Mittleman, 1996). Rather than providing a direct or unambiguous measure of the appetitive motivational characteristics of a stimulus, PROG break points are more directly a measure of how much work the organism will do in order to obtain that stimulus (Stewart, 1974). Thus, it is reasonable to view PROG performance as resulting from effort-related decision-making processes, in which the organism is making a cost/benefit choice about whether or not to continue to respond. Such choices are based in part on factors related to characteristics of the reinforcer itself, and homeostatic factors, but also involve assessments of the work-related response costs and time constraints imposed by the ratio schedule (Salamone et al., 2009).

Consistent with these concepts, effort-based decision-making procedures have been developed that offer organisms a choice between lever pressing on a PROG schedule to obtain a preferred reinforcer vs. approaching and consuming the concurrently available but relatively less preferred chow (Schweimer and Hauber, 2005; Randall et al., 2012). Rats trained on this procedure begin each session by pressing the lever, but as the ratio requirement gradually increases, they eventually stop lever pressing and switch to chow. In behavioral economic terms, the chow is serving as a low-cost substitute that is obtained when the response costs of lever pressing are too high; thus, the presence of concurrently available chow suppresses the PROG lever pressing (Figure 1). Because of the progressively incrementing work requirement and the availability of a substitute, the baseline level of lever pressing is relatively low for most animals (though there is considerable variability; see below), and chow intake

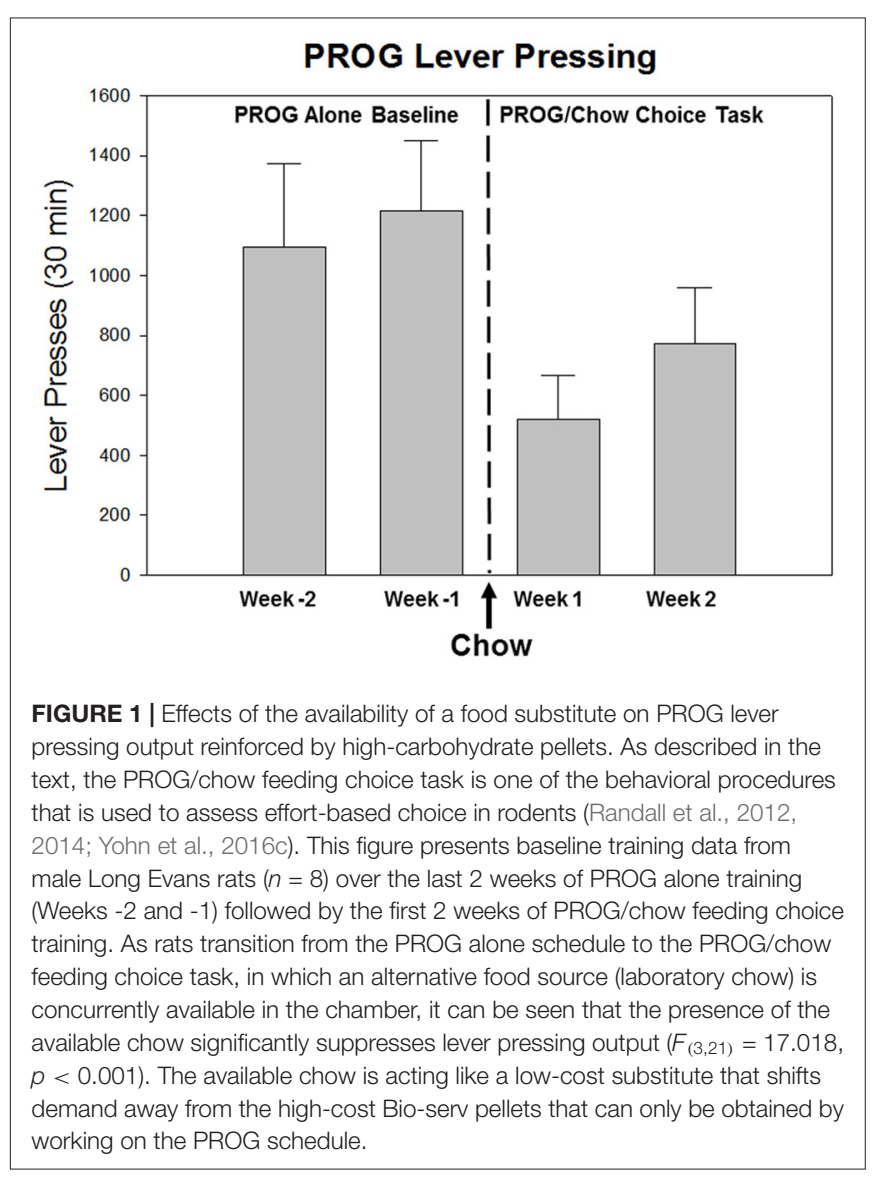

is relatively high, compared to performance on the FR5/chow feeding choice task. In the most commonly used version of this task a time out is employed (Randall et al., 2012, 2014, 2015), so that if the animal goes $2 \mathrm{~min}$ without receiving a reinforcement, the lever pressing option is no longer reinforced. The highest ratio achieved up to this time out thus serves as a measure that is equivalent to the break point. In a sense, the PROG/chow feeding choice procedure serves as a kind of ratio discounting procedure, in which the animal lever presses up to a point and then switches to the concurrently available chow when the lever pressing requirement is too high.

In rats tested on the PROG/chow feeding choice task, lever pressing and highest ratio achieved (i.e., break point) are suppressed by administration of the DA D1 antagonist ecopipam and the D2 antagonists haloperidol and eticlopride (Randall et al., 2012, 2014). Although this result in itself may not be viewed as very surprising given what is known about DA, what is most important to consider is that despite these drug-induced decreases in lever pressing, intake of the concurrently available chow was not suppressed from its relatively high control levels, and in fact tended to increase still further (Randall et al., 2012, 2014). In contrast, the manipulations that fundamentally blunt the reinforcing characteristics of food, such as reinforcer devaluation by prefeeding, or administration of cannabinoid receptor antagonists or inverse agonists that are known to act as appetite suppressants (AM4113 and AM251), strongly suppress both lever pressing and chow intake (Randall et al., 2012, 2014). 


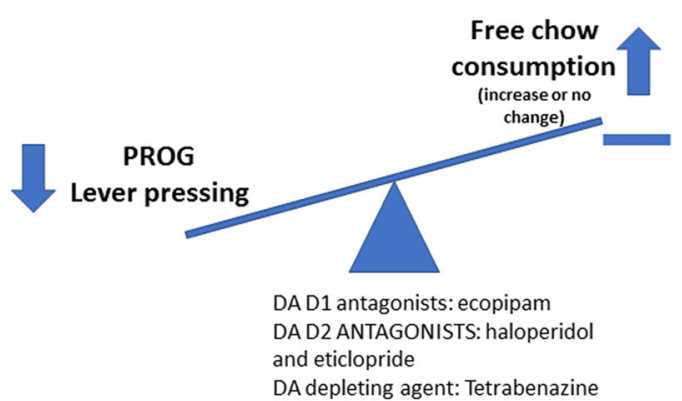

PROG

Lever pressing

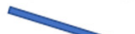

Free chow

consumption

$\mathrm{A}_{2 \mathrm{~A}}$ receptor antagonists: $\mathrm{MSX}-3$

$A_{1} / A_{2 A}$ receptor antagonist: Caffeine

DA uptake blockers: bupropion, MRZ,

lisdexamfetamine, PRX-14040 and

GBR12909

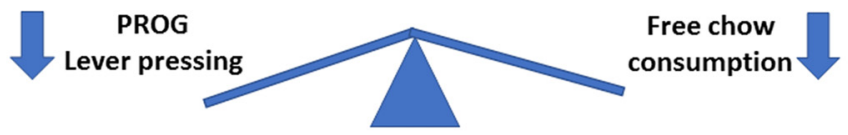

Reinforcer Devaluation by Prefeeding

Appetite suppressants: cannabinoid antagonists AM4113 and inverse agonists AM251

Norepinephrine uptake blockers: desipramine and atomoxetine

5-HT uptake blocker: fluoxetine

FIGURE 2 | Schematic drawing summarizing the effects of various pharmacological manipulations on PROG/chow feeding choice performance. Interference with dopamine (DA) transmission by giving DA antagonists or tetrabenazine decreases PROG lever pressing but does not suppress chow intake. In fact, chow intake was significantly increased by the D1 antagonist ecopipam, and also increased in animals treated with haloperidol and tetrabenazine that had high baseline rates of lever pressing (Randall et al., 2012, 2014). In contrast, interfering with the unconditioned reinforcing properties of food by reinforcer devaluation (pre-feeding) or by administration of appetite suppressant drugs (CB1 receptor antagonists/inverse agonists) decreases both PROG lever pressing and chow intake. Finally, blockade of adenosine $\mathrm{A}_{2 \mathrm{~A}}$ receptors or inhibition of DA uptake results in increased levels of PROG lever pressing (Randall et al., 2015; Yohn et al., 2016c).

Lever pressing work output is also attenuated by the VMAT-2 inhibitor and DA depleting agent tetrabenazine (Randall et al., 2014), at doses that have no effect on food intake or preference between the two foods used in the PROG/chow feeding choice task (Nunes et al., 2013a). Thus, DA antagonism and depletion are not reducing PROG lever pressing because of a general suppression of the appetitvely motivating or unconditionally reinforcing characteristics of food (Figure 2). Instead, these manipulations effectively dissociate the tendency to work for food from the unconditioned reinforcing value of food as expressed by measures of intake and preference (Salamone et al., 2016a,b,c, 2017).

\section{Progressive Ratio Choice and Bidirectional Dopaminergic Control of Effort-Based Choice}

Because of the relatively low baseline levels of lever pressing emitted by rats responding on the PROG/chow feeding choice task, this procedure provides an excellent baseline for assessing the effects of drugs that have the potential to increase selection of the high-effort PROG lever pressing (Figure 2). The adenosine $\mathrm{A}_{2 \mathrm{~A}}$ receptor antagonist MSX-3, which has some of the characteristics of minor stimulants such as caffeine, was reported to increase PROG lever pressing and decrease chow intake (Randall et al., 2012). A high effort bias (i.e., towards PROG lever pressing) also has been seen after administration of the catecholamine uptake blocker bupropion (Randall et al., 2015), and the DA uptake blockers MRZ-9547 (Sommer et al.,
2014), lisdexamfetamine (Yohn et al., 2016e), PRX-14040 (Yohn et al., 2016d) and GBR12909 (Yohn et al., 2016c). In contrast, the norepinephrine (NE) uptake blockers desipramine and atomoxetine and the 5-HT uptake blocker fluoxetine all failed to increase PROG lever pressing, in fact tending to suppress lever pressing (Yohn et al., 2016a).

These findings showing that pharmacological enhancement of DA transmission can increase selection of high-effort lever pressing illustrate the importance of DA transmission as a bi-directional regulator of effort-based choice, which is supported by research using non-pharmacological methods as well. Previous studies have observed that there was enhanced selection of high-effort instrumental actions in mice with knockdown of DA transporters (Cagniard et al., 2006), and also in mice that have increased expression of DA D2 receptors in nucleus accumbens that was induced in adulthood (Trifilieff et al., 2013). Recently, it was reported that selective chemogenetic activation of mesolimbic DA neurons, but not nigrostriatal neurons, increased responding for sucrose in rats responding on a PROG schedule (Boekhoudt et al., 2018), an effect that was characterized by increased initiation of bouts of instrumental behavior. Fischbach-Weiss et al. (2018) found that optogenetic inhibition of ventral tegmental area (VTA) DA neurons suppressed both the initiation and the maintenance of effortful operant responding on FR8 and PROG schedules. Furthermore, individual differences in performance of high-effort activities may be related to natural variations in DA transmission. As noted above, PROG/chow feeding choice performance is characterized by substantial individual differences that are very stable over 
time. Evidence indicates that rats with high PROG lever pressing output had significantly higher levels of phosphorylated DARPP-32 (DA and CAMP regulated phosphoprotein) in nucleus accumbens core neurons compared to low responders (Randall et al., 2012). This indicates that higher levels of DA-related signal transduction in post-synaptic medium spiny neurons are associated with a greater tendency to select high-effort instrumental activities. It is not clear if this finding represents a trait difference between high vs. low responders, or is instead a marker of having emitted a large number of responses. Nevertheless, an association between instrumental response output and pre- or postsynaptic markers of DA-related signaling, as seen in other studies (Sokolowski et al., 1998; Segovia et al., 2011, 2012; Howe et al., 2013; Saddoris et al., 2015; Hamid et al., 2016; Ko and Wanat, 2016; Wood et al., 2017), provides additional evidence of the importance of DA transmission in the regulation of response vigor and work output.

\section{THE USE OF EFFORT-BASED CHOICE TASKS AS PRECLINICAL TOOLS FOR ANIMAL MODELS OF PSYCHOPATHOLOGY}

\section{Impaired Behavioral Activation and Effort-Related Decision-Making in Psychopathology}

As well as providing insights into the neurochemical regulation of fundamental aspects of motivation, studies of effort-based choice are being used for modeling motivational symptoms seen in some psychiatric and neurological disorders. This development has been influenced by several factors. First, it has been recognized for some time that various psychopathologies are associated with motivational dysfunctions that reflect a lack of behavioral activation or low exertion of effort. In addition to showing positive symptoms such as hallucinations and delusions, schizophrenic patients also display negative symptoms that include motivational dysfunctions (Gard et al., 2009). Depressed patients have symptoms that include psychomotor retardation, fatigue and anergia, which are very debilitating and are related to a number of disease outcomes (Gullion and Rush, 1998; Tylee et al., 1999). Fatigue is also commonly reported in stroke patients (De Doncker et al., 2018) and people with Parkinson's disease (Chong et al., 2015). Generally speaking, these motivational dysfunctions are highly treatment resistant. For example, 5-HT uptake blockers that are commonly used to treat depression are relatively ineffective at restoring normal motivational function (Cooper et al., 2014; Fava et al., 2014; Rothschild et al., 2014). Against this backdrop, there has been a recent surge of research on humans that has specifically focused on effort-related decision making, both in people with various pathologies and healthy control participants. Wardle et al. (2011) reported that amphetamine increased selection of high-effort choices in healthy controls. Individual differences in the selection of the high-effort choice were positively associated with the degree of striatal DA release as measured by an imaging marker (Treadway et al., 2012b). Mueller et al. (2018) recently found that administration of $\alpha$-methyltyrosine, which inhibits catecholamine synthesis, disrupted the ability of healthy control subjects to effectively integrate effort requirements and reward availability. Furthermore, human studies have shown that alterations in effort-based decision making are associated with depression (Treadway et al., 2012a; Yang et al., 2014, 2016; Culbreth et al., 2017), schizophrenia (Gold et al., 2013; Culbreth et al., 2017) and Parkinson's disease (Chong et al., 2015).

\section{Animal Models of Effort-Related Motivational Dysfunction}

Based upon the foundation provided by animal research, as well as the emerging clinical literature discussed above, formal animal models of motivational pathologies have been developed, which employ tasks assessing response vigor and effort-based decision making (Salamone et al., 2006, 2015, 2016a,b,c; Simpson et al., 2011, 2012; Markou et al., 2013; Bailey et al., 2016; Der-Avakian et al., 2016). Some of this research has involved an assessment of the effort-related effects in rodents of conditions associated with depression in general, or with specific motivational symptoms such as anergia and fatigue. Furthermore, potential drug treatments have been a target for research in these models. Because stress is such an important factor in psychopathology, some studies have tried to determine the effects of stress on effort-based choice. Restraint stress has been shown to induce a low-effort bias as measured with an effort discounting task in rats (Shafiei et al., 2012), and the effort-related effects of stress involve the actions of corticotropin-releasing hormone (Bryce and Floresco, 2016).

Another condition that has been used to induce a low-effort bias in animal models is the VMAT-2 inhibitor tetrabenazine. As described above, tetrabenazine is useful in research because it is a pharmacological tool for depleting DA, however, it also is used clinically to treat Huntington's disease, and in this context has been shown to induce psychiatric side effects in humans such as depression and fatigue (Frank, 2009, 2010, 2014; Guay, 2010). While tetrabenazine has been used to produce deficits in classical animal models of depression such as the forced swim test (Tadano et al., 2000; Wang et al., 2010), recent studies have shown that tetrabenazine can induce a low-effort bias in rats tested on the FR5/chow feeding choice (Nunes et al., 2013b; Yohn et al., 2016b,d,e), PROG/chow feeding choice (Randall et al., 2014), and T-maze barrier choice tests (Yohn et al., 2015a,b). Control experiments conducted to validate the use of tetrabenazine have shown that the effort-related effects of tetrabenazine were not due to actions such as loss of appetite, changes in preference for chow vs. pellets, or preference across different concentrations of sucrose, discrimination of reinforcement magnitude, hedonic reactivity for sucrose, or reference memory (Nunes et al., 2013a; Randall et al., 2014; Pardo et al., 2015; Yohn et al., 2015a). Given this pattern of results, tetrabenazine clearly has considerable utility for inducing effort-related deficits in animals, which can serve as a baseline for identifying and characterizing potential drug targets for the treatment of effort-related motivational symptoms (Salamone et al., 2016a,b,c). 


\section{Animal Models: Drug Development}

Several monoamine uptake inhibitors are currently being used to treat depression. 5-HT uptake blockers (i.e., SSRIs) are the most commonly used antidepressants, and while they are effective at treating mood dysfunction and rumination, they have limited success in terms of restoring motivational function (Cooper et al., 2014; Fava et al., 2014; Rothschild et al., 2014). Recent experiments have been conducted to determine if monoamine uptake inhibitors with different patterns of selectivity for 5-HT, $\mathrm{NE}$ and DA uptake are able to reverse the effort-related effects of tetrabenazine. Two commonly prescribed SSRIs are fluoxetine and citalopram, and both of these drugs were unable to attenuate the effects of tetrabenazine on FR5/chow feeding choice performance (Yohn et al., 2016b,e). The NE transport inhibitor desipramine also was studied, and like the SSRIs, it was unable to reverse the effects of tetrabenazine (Yohn et al., 2016b). Despite these negative results with inhibitors of 5-HT and NE uptake, several DA uptake inhbitors have been shown to be effective at reversing the effects of tetrabenazine on effortrelated decision making. Bupropion (Welbutrin) is widely used as an antidepressant, and clinical studies have reported that this catecholamine uptake inhibitor can be more effective than SSRIs at treating fatigue symptoms (Papakostas et al., 2006; Cooper et al., 2014). Recent animal studies have shown that bupropion can reverse the effort-related effects of tetrabenazine in rats tested on the T-maze barrier choice tasks (Yohn et al., 2015a), as well as the FR5/chow feeding choice (Nunes et al., 2013b; Yohn et al., 2016b), and PROG/chow feeding choice tasks (Randall et al., 2014). Several other drugs that are capable of inhibiting DA transport (GBR12909, PRX-14040, lisdexamfetamine (Vyvanse), methylphenidate, and modafinil), also have been reported to attenuate the effort-related effects of tetrabenazine (Salamone et al., 2016c; Yohn et al., 2016b,d,e). Consistent with these findings with animal models, human studies have shown that amphetamine and methylphenidate, and the atypical DA transport inhibitor modafinil, can have positive effects on motivational symptoms in depressed patients (Stotz et al., 1999; Lam et al., 2007; Ravindran et al., 2008).

As described above, the relatively low baseline levels of lever pressing in animals tested on the PROG/chow feeding choice task makes this procedure useful for assessing the potential to increase selection of the high-effort PROG lever pressing. This line of research provides important information about the ability of drugs to produce a high-effort bias (i.e., to enhance PROG output) in the absence of tetrabenazine. Sommer et al. (2014) reported that the DA uptake inhibitor MRZ-9547 increased lever pressing in animals tested on the PROG/chow feeding choice task. Furthermore, many of the drugs that reverse the effort-related effects of tetrabenazine have been shown to increase selection of lever pressing in rats tested on the PROG/chow feeding choice procedure, including the catecholamine uptake blocker bupropion (Randall et al., 2015), and the DA uptake blockers lisdexamfetamine (Yohn et al., 2016e), PRX-14040 (Yohn et al., 2016d) and GBR12909 (Yohn et al., 2016c). As described above, these results highlight the role of DA in modulating exertion of effort, but they also point to dopaminergic manipulations as potential treatments for aspects of motivational dysfunction (Salamone et al., 2016a). However, neither the 5-HT uptake blocker fluoxetine nor NE transport inhibitors desipramine and atomoxetine were able to increase PROG lever pressing (Yohn et al., 2016a). Consistent with these findings, atomoxetine also was reported to have no effect on physical effort discounting (Hosking et al., 2015). Thus, despite studies showing that locus ceruleus neuron activity increases during exertion of physical effort (Varazzani et al., 2015), it does not appear that augmenting NE transmission pharmacologically increases selection of high effort activities. It is possible that locus ceruleus NE neuron activity is a correlate of the peripheral sympathetic activation during physical activity, or that it is correlated with attentional or other cognitive processes that are activated in parallel with the exertion of physical effort (Guillery et al., 2017).

Taking these results together, it appears that studies of effort-based decision making may ultimately contribute to the development of novel drug treatments for motivational dysfunction. In this regard, it is important to recognize that animal models of effort-based choice are not strictly speaking global models of depression, but instead are focused on modeling a particular behavioral function, and its neural basis, which may be relevant for understanding specific psychopathological symptoms. Thus, this line of research is potentially relevant for investigating motivational dysfunctions seen across many different disorders (e.g., negative symptoms of schizophrenia; see Simpson et al., 2011, 2012; Markou et al., 2013; Yohn et al., 2017a). Such an approach is consistent with the NIH RDoC (research domain criteria) initiative (Cuthbert and Insel, 2013), which focuses on identifying the neural circuits that underlie specific psychiatric symptoms.

\section{SUMMARY, GENERAL CONCLUSIONS AND BROADER IMPLICATIONS}

As discussed above, considerable evidence indicates that mesolimbic DA exerts a bi-directional control over exertion of physical effort and effort-based choice. Interference with DA transmission by DA antagonism or depletion produces a low-effort bias in rodents tested on effort-based choice tasks, while increasing DA transmission with drugs such as DA transport blockers tends to enhance selection of high-effort options. The results from these pharmacology studies are consistent with findings from recent articles using optogenetic, chemogenetic and physiological techniques. Furthermore, although the present review has focused mainly on drugs or neurotoxic lesions affecting mesolimbic DA transmission, it is important to emphasize that other signaling molecules in addition to DA, and several other brain areas, also are involved in regulating behavioral activation, response vigor, exertion of effort, and effort-based choice. These additional parts of the circuitry include neuromodulators and neurotransmitters such as adenosine (Font et al., 2008; Mingote et al., 2008; Farrar et al., 2010; Nunes et al., 2010), acetylcholine (Nunes et al., 2013b), and glutamate (Hutchison et al., 2017), and brain areas including prefrontal/anterior cingulate cortex (Walton et al., 2002, 2003, 2006; Schweimer and Hauber, 2005; Hart et al., 2017), 
and basolateral amygdala (Floresco and Ghods-Sharifi, 2007; Hart and Izquierdo, 2017). The GABAergic ventral striatopallidal pathway is a key connection in this circuitry (Mingote et al., 2008). Injections of behaviorally effective doses of the DA antagonist flupenthixol into nucleus accumbens core increases extracellular GABA in lateral ventral pallidum (Salamone et al., 2010), and injections of the GABA-A agonist muscimol into lateral ventral pallidum produces a low-effort bias similar to the effects of DA antagonism or depletion (Farrar et al., 2008; Mingote et al., 2008). Furthermore, chemogenetic inactivation of ventral striatopallidal neurons was reported to increase responding on a PROG schedule in mice (Carvalho Poyraz et al., 2016). In addition to acknowledging the distributed brain network that regulates effort-based choice, it also is important to recognize the role played by peripheral inflammation as a factor involved in regulating effort-related aspects of motivation (Nunes et al., 2014; Yohn et al., 2016a, 2017b).

Studies focusing on behavioral activation, response vigor and effort-based choice also have had an impact on computational neuroscience and economic models. Niv et al. (2007) offered a model describing the relation between increased levels of extracellular DA and response vigor. Phillips et al. (2007) proposed that the role of DA in cost/benefit analyses can be described by simple utility functions, and suggested that release of DA opens a window of opportunistic drive, in which the threshold cost expenditure to obtain reinforcers is decreased. In recent years, there has been a proliferation of modeling approaches that are intended to help characterize the roles of effort exertion and reinforcement processing in motivated behavior (Klein-Flügge et al., 2016; Białaszek et al., 2017; Pessiglione et al., 2017; Vassena et al., 2017), and disentangle exertion of effort from opportunity costs (Zénon et al., 2016). An aspect of behavioral economics that is useful for understanding the role of DA in effort-related aspects of motivation is the concept of elasticity of demand (Salamone et al., 1997, 2016a,c, 2017). Price elasticity of demand for a commodity (e.g., a reinforcer is a commodity in the context of operant behavior experiments) refers to the effect of changes in price on demand for that commodity. Low elasticity refers to a situation in which the subject is relatively insensitive to price changes, while higher levels of elasticity refers to conditions in which the sensitivity to price is greater. As described above, one way of controlling work-related response costs or prices in experiments involving instrumental behavior is to vary the ratio requirement of the lever pressing task. Previous work has shown that neurotoxic depletions of accumbens DA make animals more sensitive to the ratio requirements on ratio schedules (Aberman and Salamone, 1999; Ishiwari et al., 2004), and this type of effect has consistently been interpreted as representing a role for DA in mediating elasticity of demand for food (Salamone et al., 1997, 2009; Aberman and Salamone, 1999). Although these earlier studies did not provide mathematical indices of elasticity of demand, recent studies demonstrated that low doses of the DA antagonist haloperidol and the DA depleting agent tetrabenazine increased point elasticity of demand (Salamone et al., 2017). Taken together, these findings are consistent with a recent article reporting that DA D2 receptor knockout also increased elasticity of demand (Soto et al., 2016).

In addition to providing important basic science information about the neural regulation of motivated behavior, effort-based decision making research has several practical applications. Within the fields of industrial/organizational psychology and behavioral health, it is becoming more and more emphasized that effort/reward trade-offs can be a substantial source of stress in the workplace (Eddy et al., 2017, 2018). As reviewed above, studies of effort-related decision making in humans have the potential to offer important insights into motivational dysfunction in psychopathology. Furthermore, tasks that assess effort-based choice are useful for developing animal models of some of the motivational symptoms that are seen in people with various psychiatric and neurological disorders (e.g., depression, schizophrenia and Parkinson's disease). Exertion of effort in pursuit of rewards is also a feature of drug self-adminitration in humans and other animals (Vezina et al., 2002; Venugopalan et al., 2011). Addicts will exert considerable effort to obtain their preferred drug, and will overcome numerous obstacles and constraints to do so. Furthermore, drug abstinence has been shown to be associated with psychomotor retardation and reduced selection of high-effort options in humans (Volkow et al., 2001) and animal models (Thompson et al., 2017).

Although it is often the case that animal models are designed to target neuropsychiatric disorders, it is nevertheless true that most animal models provide behavioral phenotypes that mimic specific symptoms or dysfunctions rather than entire disorders. Studies of effort-related choice, in so far as they contribute to animal models in psychiatry, are indeed designed to focus on modeling specific symptoms and circuit dysfunctions, and are not intended to provide global models of depression or schizophrenia. Nevertheless, this line of work may offer further insights into the neural circuits underlying motivational dysfunction in humans, and may also lead to the identification of drug targets that improve treatment outcomes for specific motivational symptoms that can be highly problematic and debilitating.

\section{ETHICS STATEMENT}

This research was carried out in accordance with US NIH guidelines, and the protocol was approved by the University of Connecticut Institutional Animal Care and Use Committee.

\section{AUTHOR CONTRIBUTIONS}

JDS, MC, J-HY, RR and RP contributed to the writing of this manuscript. RR and MC also constructed the figures.

\section{ACKNOWLEDGMENTS}

Much of the work cited in this review was supported by grants to JDS from the US NIH/NIMH R03MH112984, Shire and Prexa, and to MC from PSI2015-68497-R grant. 


\section{REFERENCES}

Aberman, J. E., and Salamone, J. D. (1999). Nucleus accumbens dopamine depletions make rats more sensitive to high ratio requirements but do not impair primary food reinforcement. Neuroscience 92, 545-552. doi: 10.1016/s0306-4522(99)00004-4

Arnold, J. M., and Roberts, D. C. S. (1997). A critique of fixed and progressive ratio schedules used to examine the neural substrates of drug reinforcement. Pharmacol. Biochem. Behav. 57, 441-447. doi: 10.1016/s0091-3057(96)00445-5

Bailey, M. R., Simpson, E. H., and Balsam, P. D. (2016). Neural substrates underlying effort, time, and risk-based decision making in motivated behavior. Neurobiol. Learn. Mem. 133, 233-256. doi: 10.1016/j.nlm.2016.07.015

Bardgett, M. E., Depenbrock, M., Downs, N., Points, M., and Green, L. (2009). Dopamine modulates effort-based decision making in rats. Behav. Neurosci. 123, 242-251. doi: 10.1037/a0014625

Bentzley, B. S., and Aston-Jones, G. (2015). Orexin-1 receptor signaling increases motivation for cocaine-associated cues. Eur. J. Neurosci. 41, 1149-1156. doi: 10.1111/ejn.12866

Bentzley, B. S., Fender, K. M., and Aston-Jones, G. (2013). The behavioral economics of drug self-administration: a review and new analytical approach for within-session procedures. Psychopharmacology 226, 113-125. doi: 10.1007/s00213-012-2899-2

Bentzley, B. S., Jhou, T. C., and Aston-Jones, G. (2014). Economic demand predicts addiction-like behavior and therapeutic efficacy of oxytocin in the rat. Proc. Natl. Acad. Sci. U S A 111, 11822-11827. doi: 10.1073/pnas.1406324111

Białaszek, W., Marcowski, P., and Ostaszewski, P. (2017). Physical and cognitive effort discounting across different reward magnitudes: tests of discounting models. PLoS One 12:e0182353. doi: 10.1371/journal.pone.0182353

Bickel, W. K., Marsch, L. A., and Carroll, M. E. (2000). Deconstructing relative reinforcing efficacy and situating the measures of pharmacological reinforcement with behavioral economics: a theoretical proposal. Psychopharmacology 153, 44-56. doi: 10.1007/s002130000589

Boekhoudt, L., Wijbrans, E. C., Man, J. H. K., Luijendijk, M. C. M., de Jong, J. W., van der Plasse, G., et al. (2018). Enhancing excitability of dopamine neurons promotes motivational behaviour through increased action initiation. Eur. Neuropsychopharmacol. 28, 171-184. doi: 10.1016/j.euroneuro.2017.11.005

Bryce, C. A., and Floresco, S. B. (2016). Perturbations in effort-related decision-making driven by acute stress and corticotropin-releasing factor. Neuropsychopharmacology 41, 2147-2159. doi: 10.1038/npp.2016.15

Cagniard, B., Balsam, P. D., Brunner, D., and Zhuang, X. (2006). Mice with chronically elevated dopamine exhibit enhanced motivation, but not learning, for a food reward. Neuropsychopharmacology 31, 1362-1370. doi: 10.1038/sj. npp. 1300966

Carvalho Poyraz, F., Holzner, E., Bailey, M. R., Meszaros, J., Kenney, L., Kheirbek, M. A., et al. (2016). Decreasing striatopallidal pathway function enhances motivation by energizing the initiation of goal-directed action. J. Neurosci. 36, 5988-6001. doi: 10.1523/jneurosci.0444-16.2016

Chong, T. T., Bonnelle, V., Manohar, S., Veromann, K., Muhammed, K., Tofaris, G. K., et al. (2015). Dopamine enhances willingness to exert effort for reward in Parkinson's disease. Cortex 69, 40-46. doi: 10.1016/j.cortex.2015. 04.003

Cooper, J. A., Tucker, V. L., and Papakostas, G. I. (2014). Resolution of sleepiness and fatigue: a comparison of bupropion and selective serotonin reuptake inhibitors in subjects with major depressive disorder achieving remission at doses approved in the European Union. J. Psychopharmacol. 28, 118-124. doi: 10.1177/0269881113514878

Cousins, M. S., Atherton, A., Turner, L., and Salamone, J. D. (1996). Nucleus accumbens dopamine depletions alter relative response allocation in a T-maze cost/benefit task. Behav. Brain Res. 74, 189-197. doi: 10.1016/01664328(95)00151-4

Cousins, M. S., Sokolowski, J. D., and Salamone, J. D. (1993). Different effects of nucleus accumbens and ventrolateral striatal dopamine depletions on instrumental response selection in the rat. Pharmacol. Biochem. Behav. 46, 943-951. doi: 10.1016/0091-3057(93)90226-j

Cousins, M. S., Wei, W., and Salamone, J. D. (1994). Pharmacological characterization of performance on a concurrent lever pressing/feeding choice procedure: effects of dopamine antagonist, cholinomimetic, sedative and stimulant drugs. Psychopharmacology 116, 529-537. doi: 10.1007/bf02247489
Culbreth, A. J., Moran, E. K., and Barch, D. M. (2017). Effort-cost decisionmaking in psychosis and depression: could a similar behavioral deficit arise from disparate psychological and neural mechanisms? Psychol. Med. 11, 1-16. doi: 10.1017/s0033291717002525

Cuthbert, B. N., and Insel, T. R. (2013). Toward the future of psychiatric diagnosis: the seven pillars of RDoC. BMC Med. 11:126. doi: 10.1186/1741-7015-11-126

De Doncker, W., Dantzer, R., Ormstad, H., and Kuppuswamy, A. (2018). Mechanisms of poststroke fatigue. J. Neurol. Neurosurg. Psychiatry 89, 287-293. doi: 10.1136/jnnp-2017-316007

Denk, F., Walton, M. E., Jennings, K. A., Sharp, T., Rushworth, M. F., and Bannerman, D. M. (2005). Differential involvement of serotonin and dopamine systems in cost-benefit decisions about delay or effort. Psychopharmacology 179, 587-596. doi: 10.1007/s00213-004-2059-4

Der-Avakian, A., Barnes, S. A., Markou, A., and Pizzagalli, D. A. (2016). Translational assessment of reward and motivational deficits in psychiatric disorders. Curr. Top. Behav. Neurosci. 28, 231-262. doi: 10.1007 /7854_2015_5004

Eddy, P., Wertheim, E. H., Hale, M. W., and Wright, B. J. (2018). A systematic review and meta-analysis of the effort-reward imbalance model of workplace stress and hypothalamic-pituitary-adrenal axis measures of stress. Psychosom. Med. 80, 103-113. doi: 10.1097/psy.0000000000000505

Eddy, P., Wertheim, E. H., Kingsley, M., and Wright, B. J. (2017). Associations between the effort-reward imbalance model of workplace stress and indices of cardiovascular health: a systematic review and meta-analysis. Neurosci. Biobehav. Rev. 83, 252-266. doi: 10.1016/j.neubiorev.2017.10.025

Farrar, A. M., Font, L., Pereira, M., Mingote, S. M., Bunce, J. G., Chrobak, J. J., et al. (2008). Forebrain circuitry involved in effort-related choice: injections of the $\mathrm{GABA}_{\mathrm{A}}$ agonist muscimol into ventral pallidum alters response allocation in food-seeking behavior. Neuroscience 152, 321-330. doi: 10.1016/j.neuroscience. 2007.12.034

Farrar, A. M., Segovia, K. N., Randall, P. A., Nunes, E. J., Collins, L. E., Stopper, C. M., et al. (2010). Nucleus accumbens and effort-related functions: behavioral and neural markers of the interactions between adenosine $A_{2 A}$ and dopamine $\mathrm{D}_{2}$ receptors. Neuroscience 166, 1056-1067. doi: 10.1016/j. neuroscience.2009.12.056

Fava, M., Ball, S., Nelson, J. C., Sparks, J., Konechnik, T., Classi, P., et al. (2014). Clinical relevance of fatigue as a residual symptom in major depressive disorder. Depress. Anxiety 31, 250-257. doi: 10.1002/da.22199

Fischbach-Weiss, S., Reese, R. M., and Janak, P. (2018). Inhibiting mesolimbic dopamine neurons reduces the initiation and maintenance of instrumental responding. Neuroscience 372, 306-315. doi: 10.1016/j.neuroscience.2017. 12.003

Floresco, S. B. (2015). The nucleus accumbens: an interface between cognition, emotion, and action. Annu. Rev. Psychol. 66, 25-252. doi: 10.1146/annurevpsych-010213-115159

Floresco, S. B., and Ghods-Sharifi, S. (2007). Amygdala-prefrontal cortical circuitry regulates effort-based decision making. Cereb. Cortex 17, 251-260. doi: 10.1093/cercor/bhj143

Floresco, S. B., St. Onge, J. R., Ghods-Sharifi, S., and Winstanley, C. A. (2008a). Cortico-limbic-striatal circuits subserving different forms of cost-benefit decision making. Cogn. Affect. Behav. Neurosci. 8, 375-389. doi: 10.3758/cabn. 8.4.375

Floresco, S. B., Tse, M. T., and Ghods-Sharifi, S. (2008b). Dopaminergic and glutamatergic regulation of effort- and delay-based decision making. Neuropsychopharmacology 33, 1966-1979. doi: 10.1038/sj.npp. 1301565

Font, L., Mingote, S., Farrar, A. M., Pereira, M., Worden, L., Stopper, C., et al. (2008). Intra-accumbens injections of the adenosine $A_{2 A}$ agonist CGS 21680 affect effort-related choice behavior in rats. Psychopharmacology 199, 515-526. doi: 10.1007/s00213-008-1174-z

Frank, S. (2009). Tetrabenazine as anti-chorea therapy in Huntington Disease: an open-label continuation study. Huntington Study Group/TETRA-HD Investigators. BMC Neurol. 9:62. doi: 10.1186/1471-2377-9-62

Frank, S. (2010). Tetrabenazine: the first approved drug for the treatment of chorea in US patients with Huntington's disease. Neuropsychiatr. Dis. Treat. 5, 657-665. doi: 10.2147/ndt.s6430

Frank, S. (2014). Treatment of Huntington's disease. Neurotherapeutics 11, 153-160. doi: 10.1007/s13311-013-0244-Z 
Gard, D. E., Fisher, M., Garrett, C., Genevsky, A., and Vinogradov, S. (2009). Motivation and its relationship to neurocognition, social cognition, and functional outcome in schizophrenia. Schizophr. Res. 115, 74-81. doi: 10.1016/j. schres.2009.08.015

Gold, J. M., Strauss, G. P., Waltz, J. A., Robinson, B. M., Brown, J. K., and Frank, M. J. (2013). Negative symptoms of schizophrenia are associated with abnormal effort-cost computations. Biol. Psychiatry 74, 130-136. doi: 10.1016/j. biopsych.2012.12.022

Guay, D. R. (2010). Tetrabenazine, a monoamine-depleting drug used in the treatment of hyperkinectic movement disorders. Am. J. Geriatr. Pharmacother. 8, 331-373. doi: 10.1016/j.amjopharm.2010.08.006

Guillery, E., Mouraux, A., Thonnard, J. L., and Legrain, V. (2017). Mind your grip: even usual dexterous manipulation requires high level cognition. Front. Behav. Neurosci. 11:220. doi: 10.3389/fnbeh.2017.00220

Gullion, C. M., and Rush, A. J. (1998). Toward a generalizable model of symptoms in major depressive disorder. Biol. Psychiatry 44, 959-972. doi: 10.1016/s00063223(98)00235-2

Hamid, A. A., Pettibone, J. R., Mabrouk, O. S., Hetrick, V. L., Schmidt, R., Vander Weele, C. M., et al. (2016). Mesolimbic dopamine signals the value of work. Nat. Neurosci. 19, 117-126. doi: 10.1038/nn.4173

Hamill, S., Trevitt, J. T., Nowend, K. L., Carlson, B. B., and Salamone, J. D. (1999). Nucleus accumbens dopamine depletions and time-constrained progressive ratio performance: effects of different ratio requirements. Pharmacol. Biochem. Behav. 64, 21-27. doi: 10.1016/s0091-3057(99)00092-1

Hart, E. E., Gerson, J. O., Zoken, Y., Garcia, M., and Izquierdo, A. (2017). Anterior cingulate cortex supports effort allocation towards a qualitatively preferred option. Eur. J. Neurosci. 46, 1682-1688. doi: 10.1111/ejn.13608

Hart, E. E., and Izquierdo, A. (2017). Basolateral amygdala supports the maintenance of value and effortful choice of a preferred option. Eur. J. Neurosci. 45, 388-397. doi: 10.1111/ejn.13497

Hauber, W., and Sommer, S. (2009). Prefrontostriatal circuitry regulates effort-related decision making. Cereb. Cortex 19, 2240-2247. doi: 10.1093/cercor/bhn241

Heinz, A. J., Lilje, T. C., Kassel, J. D., and de Wit, H. (2012). Quantifying reinforcement value and demand for psychoactive substances in humans. Curr. Drug Abuse Rev. 5, 257-272. doi: 10.2174/1874473711205040002

Heyman, G. M. (2000). An economic approach to animal models of alcoholism. Alcohol Res. Health 24, 132-139.

Hosking, J. G., Floresco, S. B., and Winstanley, C. A. (2015). Dopamine antagonism decreases willingness to expend physical, but not cognitive, effort: a comparison of two rodent cost/benefit decision-making tasks. Neuropsychopharmacology 40, 1005-1015. doi: 10.1038/npp. 2014.285

Howe, M. W., Tierney, P. L., Sandberg, S. G., Phillips, P. E., and Graybiel, A. M. (2013). Prolonged dopamine signalling in striatum signals proximity and value of distant rewards. Nature 500, 575-579. doi: 10.1038/nature12475

Hursh, S. R., and Winger, G. (1995). Normalized demand for drugs and other reinforcers. J. Exp. Anal. Behav. 64, 373-384. doi: 10.1901/jeab.1995. 64-373

Hutchison, M. A., Gu, X., Adrover, M. F., Lee, M. R., Hnasko, T. S., Alvarez, V. A., et al. (2017). Genetic inhibition of neurotransmission reveals role of glutamatergic input to dopamine neurons in high-effort behavior. Mol. Psychiatry doi: 10.1038/mp.2017.7 [Epub ahead of print].

Ishiwari, K., Weber, S. M., Mingote, S., Correa, M., and Salamone, J. D. (2004). Accumbens dopamine and the regulation of effort in food-seeking behavior: modulation of work output by different ratio or force requirements. Behav. Brain Res. 151, 83-91. doi: 10.1016/j.bbr.2003.08.007

Klein-Flügge, M. C., Kennerley, S. W., Friston, K., and Bestmann, S. (2016). Neural signatures of value comparison in human cingulate cortex during decisions requiring an effort-reward trade-off. J. Neurosci. 36, 10002-10015. doi: 10.1523/JNEUROSCI.0292-16.2016

Ko, D., and Wanat, M. J. (2016). Phasic dopamine transmission reflects initiation vigor and exerted effort in an action- and region-specific manner. J. Neurosci. 36, 2202-2211. doi: 10.1523/JNEUROSCI.1279-15.2016

Koch, M., Schmid, A., and Scnhnitzler, H. U. (2000). Role of nucleus accumbens dopamine D1 and D2 receptors in instrumental and Pavlovian paradigms of conditioned reward. Psychopharmacology 152, 67-73. doi: $10.1007 / \mathrm{s} 002130000505$
Lam, J. Y., Freeman, M. K., and Cates, M. E. (2007). Modafinil augmentation for residual symptoms of fatigue in patients with a partial response to antidepressants. Ann. Pharmacother. 41, 1005-1012. doi: 10.1345/aph.1h526

Madden, G. J., Bickel, W. K., and Jacobs, E. A. (2000). Three predictions of the economic concept of unit price in a choice context. J. Exp. Anal. Behav. 73, 45-64. doi: 10.1901/jeab.2000.73-45

Madden, G. J., and Kalman, D. (2010). Effects of bupropion on simulated demand for cigarettes and the subjective effects of smoking. Nicotine Tob. Res. 12, 416-422. doi: 10.1093/ntr/ntq018

Madden, G. J., Smethells, J. R., Ewan, E. E., and Hursh, S. R. (2007). Tests of behavioral-economic assessments of relative reinforcer efficacy II: economic complements. J. Exp. Anal. Behav. 88, 355-367. doi: 10.1901/jeab.2007.88-355

Mai, B., Sommer, S., and Hauber, W. (2012). Motivational states influence effortbased decision making in rats: the role of dopamine in the nucleus accumbens. Cogn. Affect. Behav. Neurosci. 12, 74-84. doi: 10.3758/s13415-011-0068-4

Marinelli, M., Barrot, M., Simon, H., Oberlander, C., Dekeyne, A., Le Moal, M., et al. (1998). Pharmacological stimuli decreasing nucleus accumbens dopamine can act as positive reinforcers but have a low addictive potential. Eur. J. Neurosci. 10, 3269-3275. doi: 10.1046/j.1460-9568.1998.00340.x

Markou, A., Salamone, J. D., Bussey, T. J., Mar, A. C., Brunner, D., Gilmour, G., et al. (2013). Measuring reinforcement learning and motivation constructs in experimental animals: relevance to the negative symptoms of schizophrenia. Neurosci. Biobehav. Rev. 37, 2149-2165. doi: 10.1016/j.neubiorev.2013. 08.007

Mingote, S., Font, L., Farrar, A. M., Vontell, R., Worden, L. T., Stopper, C. M., et al. (2008). Nucleus accumbens adenosine $A_{2 A}$ receptors regulate exertion of effort by acting on the ventral striatopallidal pathway. J. Neurosci. 28, 9037-9046. doi: 10.1523/JNEUROSCI.1525-08.2008

Mott, A. M., Nunes, E. J., Collins, L. E., Port, R. G., Sink, K. S., Hockemeyer, J., et al. (2009). The adenosine $\mathrm{A}_{2 \mathrm{~A}}$ antagonist MSX-3 reverses the effects of the dopamine antagonist haloperidol on effort-related decision making in a T-maze cost/benefit procedure. Psychopharmacology 204, 103-112. doi: 10.1007/s00213-008-1441-Z

Mueller, S. V., Morishima, Y., Schwab, S., Wiest, R., Federspiel, A., and Hasler, G. (2018). Neural correlates of impaired reward-effort integration in remitted bulimia nervosa. Neuropsychopharmacology 43, 868-876. doi: 10.1038/npp. 2017.277

Nicola, S. M. (2016). Reassessing wanting and liking in the study of mesolimbic influence on food intake. Am. J. Physiol. Regul. Integr. Comp. Physiol. 311, R811-R840. doi: 10.1152/ajpregu.00234.2016

Niv, Y., Daw, N. D., Joel, D., and Dayan, P. (2007). Tonic dopamine: opportunity costs and the control of response vigor. Psychopharmacology 191, 507-520. doi: 10.1007/s00213-006-0502-4

Nowend, K. L., Arizzi, M., Carlson, B. B., and Salamone, J. D. (2001). D1 or D2 antagonism in nucleus accumbens core or dorsomedial shell suppresses lever pressing for food but leads to compensatory increases in chow consumption. Pharmacol. Biochem. Behav. 69, 373-382. doi: 10.1016/s00913057(01)00524-x

Nunes, E. J., Randall, P. A., Estrada, A., Epling, B., Hart, E., Lee, C. E., et al. (2014). Effort-related motivational effects of the pro-inflammatory cytokine interleukin 1- $\beta$ : studies with the concurrent fixed ratio 5/chow feeding choice task. Psychopharmacology 231, 727-736. doi: 10.1007/s00213-013 $-3285-4$

Nunes, E. J., Randall, P. A., Hart, E. E., Freeland, C., Yohn, S. E., Baqi, Y., et al. (2013a). Effort-related motivational effects of the VMAT-2 inhibitor tetrabenazine: implications for animal models of the motivational symptoms of depression. J. Neurosci. 33, 19120-19130. doi: 10.1523/jneurosci.2730-13.2013

Nunes, E. J., Randall, P. A., Podurgiel, S., Correa, M., and Salamone, J. D. (2013b). Nucleus accumbens neurotransmission and effort-related choice behavior in food motivation: effects of drugs acting on dopamine, adenosine, and muscarinic acetylcholine receptors. Neurosci. Biobehav. Rev. 37, 2015-2025. doi: 10.1016/j.neubiorev.2013.04.002

Nunes, E. J., Randall, P. A., Santerre, J. L., Given, A. B., Sager, T. N., Correa, M. et al. (2010). Differential effects of selective adenosine antagonists on the effort-related impairments induced by dopamine D1 and D2 antagonism. Neuroscience 170, 268-280. doi: 10.1016/j.neuroscience.2010.05.068

Ostrander, S., Cazares, V. A., Kim, C., Cheung, S., Gonzalez, I., and Izquierdo, A. (2011). Orbitofrontal cortex and basolateral amygdala lesions result in 
suboptimal and dissociable reward choices on cue-guided effort in rats. Behav. Neurosci. 125, 350-359. doi: 10.1037/a0023574

Papakostas, G. I., Nutt, D. J., Hallett, L. A., Tucker, V. L., Krishen, A., and Fava, M. (2006). Resolution of sleepiness and fatigue in major depressive disorder: a comparison of bupropion and the selective serotonin reuptake inhibitors. Biol. Psychiatry 60, 1350-1355. doi: 10.1016/j.biopsych.2006. 06.015

Pardo, M., López-Cruz, L., San Miguel, N., Salamone, J. D., and Correa, M. (2015). Selection of sucrose concentration depends on the effort required to obtain it: studies using tetrabenazine, $\mathrm{D}_{1}, \mathrm{D}_{2}$, and $\mathrm{D}_{3}$ receptor antagonists. Psychopharmacology 232, 2377-2391. doi: 10.1007/s00213-015-3872-7

Pardo, M., Lopez-Cruz, L., Valverde, O., Ledent, C., Baqi, Y., Müller, C. E., et al. (2012). Adenosine $A_{2 A}$ receptor antagonism and genetic deletion attenuate the effects of dopamine $\mathrm{D}_{2}$ antagonism on effort-based decision making in mice. Neuropharmacology 62, 2068-2077. doi: 10.1016/j.neuropharm.2011. 12.033

Pessiglione, M., Vinckier, F., Bouret, S., Daunizeau, J., and Le Bouc, R. (2017). Why not try harder? Computational approach to motivation deficits in neuropsychiatric diseases. Brain doi: 10.1093/brain/awx278 [Epub ahead of print].

Phillips, P. E., Walton, M. E., and Jhou, T. C. (2007). Calculating utility: preclinical evidence for cost-benefit analysis by mesolimbic dopamine. Psychopharmacology 191, 483-495. doi: 10.1007/s00213-006-0626-6

Premack, D. (1959). Toward empirical behavior laws. I: positive reinforcement. Psychol. Rev. 66, 219-233. doi: 10.1037/h0040891

Rachlin, H. (2003). "Economic concepts in the behavioral study of addiction," in Choice, Behavioral Economics and Addiction, eds R. E. Vuchinich and N. Heather (Oxford: Elsevier), 129-149.

Randall, P. A., Lee, C. A., Nunes, E. J., Yohn, S. E., Nowak, V., Khan, B., et al. (2014). The VMAT-2 inhibitor tetrabenazine affects effort-related decision making in a progressive ratio/chow feeding choice task: reversal with antidepressant drugs. PLoS One 9:e99320. doi: 10.1371/journal.pone. 0099320

Randall, P. A., Lee, C. E., Podurgiel, S. J., Hart, E., Yohn, S. E., Jones, M., et al. (2015). Bupropion increases selection of high effort activity in rats tested on a progressive ratio/chow feeding choice procedure: implications for treatment of effort-related motivational symptoms. Int. J. Neuropsychopharmacol. 18:pyu017. doi: 10.1093/ijnp/pyu017

Randall, P. A., Pardo, M., Nunes, E. J., López Cruz, L., Vemuri, V. K., Makriyannis, A., et al. (2012). Dopaminergic modulation of effortrelated choice behavior as assessed by a progressive ratio chow task: pharmacological studies and role of individual differences. PLoS One 7:e47934. doi: 10.1371/journal.pone.0047934

Ravindran, A. V., Kennedy, S. H., O’Donovan, M. C., Fallu, A., Camacho, F., and Binder, C. E. (2008). Osmotic-release oral system methylphenidate augmentation of antidepressant monotherapy in major depressive disorder: results of a double-blind, randomized, placebo-controlled trial. J. Clin. Psychiatry 69, 87-94. doi: 10.4088/jcp.v69n0112

Robles, C. F., and Johnson, A. W. (2017). Disruptions in effort-based decisionmaking and consummatory behavior following antagonism of the dopamine D2 receptor. Behav. Brain Res. 320, 431-439. doi: 10.1016/j.bbr.2016. 10.043

Rothschild, A. J., Raskin, J., Wang, C. N., Marangell, L. B., and Fava, M. (2014). The relationship between change in apathy and changes in cognition and functional outcomes in currently non-depressed SSRI-treated patients with major depressive disorder. Compr. Psychiatry 55, 1-10. doi: 10.1016/j. comppsych.2013.08.008

Saddoris, M. P., Cacciapaglia, F., Wightman, R. M., and Carelli, R. M. (2015). Differential dopamine release dynamics in the nucleus accumbens core and shell reveal complementary signals for error prediction and incentive motivation. J. Neurosci. 35, 11572-11582. doi: 10.1523/JNEUROSCI.2344 $-15.2015$

Salamone, J. D., Arizzi, M., Sandoval, M. D., Cervone, K. M., and Aberman, J. E. (2002). Dopamine antagonsts alter response allocation but do not suppress appetite for food in rats: contrast between the effects of SKF 83566, raclopride, and fenfluramine on a concurrent choice task. Psychopharmacology 160, 371-380. doi: 10.1007/s00213-001-0994-x

Salamone, J. D., and Correa, M. (2002). Motivational views of reinforcement: implications for understanding the behavioral functions of nucleus accumbens dopamine. Behav. Brain Res. 137, 3-25. doi: 10.1016/s0166-4328(02) 00282-6

Salamone, J. D., and Correa, M. (2012). The mysterious motivational functions of mesolimbic dopamine. Neuron 76, 470-485. doi: 10.1016/j.neuron.2012.10.021

Salamone, J. D., Correa, M., Farrar, A., and Mingote, S. M. (2007). Effort-related functions of nucleus accumbens dopamine and associated forebrain circuits. Psychopharmacology 191, 461-482. doi: 10.1007/s00213-006 $-0668-9$

Salamone, J. D., Correa, M., Farrar, A. M., Nunes, E. J., and Pardo, M. (2009). Dopamine, behavioral economics, and effort. Front. Behav. Neurosci. 3:13. doi: 10.3389/neuro.08.013.2009

Salamone, J. D., Correa, M., Farrar, A. M., Nunes, E. J., and Collins, L. E. (2010). Role of dopamine-adenosine interactions in the brain circuitry regulating effort-related decision making: insights into pathological aspects of motivation. Future Neurol. 5, 377-392. doi: 10.2217/fnl.10.19

Salamone, J. D., Correa, M., Mingote, S. M., Weber, S. M., and Farrar, A. M. (2006). Nucleus accumbens dopamine and the forebrain circuitry involved in behavioral activation and effort-related decision making: implications for understanding anergia and psychomotor slowing in depression. Curr. Psychiatry Rev. 2, 267-280. doi: 10.2174/157340006776 875914

Salamone, J. D., Correa, M., Yohn, S. E., Yang, J. H., Somerville, M., Rotolo, R. A., et al. (2017). Behavioral activation, effort-based choice, and elasticity of demand for motivational stimuli: basic and translational neuroscience approaches. Motiv. Sci. 3, 208-229. doi: $10.1037 / \operatorname{mot} 0000070$

Salamone, J. D., Cousins, M. S., and Bucher, S. (1994). Anhedonia or anergia? Effects of haloperidol and nucleus accumbens dopamine depletion on instrumental response selection in a T-maze cost/benefit procedure. Behav. Brain Res. 65, 221-229. doi: 10.1016/0166-4328(94)90108-2

Salamone, J. D., Cousins, M. S., and Snyder, B. J. (1997). Behavioral functions of nucleus accumbens dopamine: empirical and conceptual problems with the anhedonia hypothesis. Neurosci. Biobehav. Rev. 21, 341-359. doi: 10.1016/s0149-7634(96)00017-6

Salamone, J. D., Koychev, I., Correa, M., and McGuire, P. (2015). Neurobiological basis of motivational deficits in psychopathology. Eur. Neuropsychopharmacol. 25, 1225-1238. doi: 10.1016/j.euroneuro.2014.08.014

Salamone, J. D., Correa, M., Yohn, S., Lopez-Cruz, L., San Miguel, N., and Alatorre, L. (2016a). The pharmacology of effort-related choice behavior: dopamine, depression, and individual differences. Behav. Processes 127, 3-17. doi: 10.1016/j.beproc.2016.02.008

Salamone, J. D., Pardo, M., Yohn, S. E., López-Cruz, L., SanMiguel, N., and Correa, M. (2016b). Mesolimbic dopamine and the regulation of motivated behavior. Curr. Top. Behav. Neurosci. 27, 231-257. doi: 10.1007/7854_2015_383

Salamone, J. D., Yohn, S., López-Cruz, L., San Miguel, N., and Correa, M. (2016c). Activational and effort-related aspects of motivation: neural mechanisms and implications for psychopathology. Brain 139, 1325-1347. doi: 10.1093/brain/aww050

Salamone, J. D., Steinpreis, R. E., McCullough, L. D., Smith, P., Grebel, D., and Mahan, K. (1991). Haloperidol and nucleus accumbens dopamine depletion suppress lever pressing for food but increase free food consumption in a novel food choice procedure. Psychopharmacology 104, 515-521. doi: $10.1007 /$ bf02245659

Schmelzeis, M. C., and Mittleman, G. (1996). The hippocampus and reward: effects of hippocampal lesions on progressive-ratio responding. Behav. Neurosci. 110, 1049-1066. doi: 10.1037/0735-7044.110.5.1049

Schweimer, J., and Hauber, W. (2005). Involvement of the rat anterior cingulate cortex in control of instrumental responses guided by reward expectancy. Learn. Mem. 12, 334-342. doi: 10.1101/lm.90605

Segovia, K. N., Correa, M., Lennington, J. B., Conover, J. C., and Salamone, J. D. (2012). Changes in nucleus accumbens and neostriatal c-Fos and DARPP-32 immunoreactivity during different stages of food-reinforced instrumental training. Eur. J. Neurosci. 35, 1354-1367. doi: 10.1111/j.1460-9568.2012. 08036. $\mathrm{x}$

Segovia, K. N., Correa, M., and Salamone, J. D. (2011). Slow phasic changes in nucleus accumbens dopamine release during fixed ratio acquisition: a microdialysis study. Neuroscience 196, 188-198. doi: 10.1016/j.neuroscience. 2011.07.078 
Shafiei, N., Gray, M., Viau, V., and Floresco, S. B. (2012). Acute stress induces selective alterations in cost/benefit decision-making. Neuropsychopharmacology 37, 2194-2209. doi: 10.1038/npp.2012.69

Simpson, E. H., Kellendonk, C., Ward, R. D., Richards, V., Lipatova, O., Fairhurst, S., et al. (2011). Pharmacologic rescue of motivational deficit in an animal model of the negative symptoms of schizophrenia. Biol. Psychiatry 69 , 928-935. doi: 10.1016/j.biopsych.2011.01.012

Simpson, E. H., Waltz, J. A., Kellendonk, C., and Balsam, P. D. (2012). Schizophrenia in translation: dissecting motivation in schizophrenia and rodents. Schizophr. Bull. 38, 1111-1117. doi: 10.1093/schbul/sbs114

Sink, K. S., Vemuri, V. K., Olszewska, T., Makriyannis, A., and Salamone, J. D. (2008). Cannabinoid CB1 antagonists and dopamine antagonists produce different effects on a task involving response allocation and effortrelated choice in food-seeking behavior. Psychopharmacology 196, 565-574. doi: 10.1007/s00213-007-0988-4

Skinner, B. F. (1953). Science and Human Behavior. New York, NY: Macmillan.

Skjoldager, P., Pierre, P. J., and Mittlman, G. (1993). Reinforcer magnitude and progressive ratio responding: effects of increased effort, prefeeding, and extinction. Learn. Motiv. 24, 303-343. doi: 10.1006/lmot. 1993.1019

Sokolowski, J. D., Conlan, A. N., and Salamone, J. D. (1998). A microdialysis study of nucleus accumbens core and shell dopamine during operant responding in the rat. Neuroscience 86, 1001-1009. doi: 10.1016/s0306-4522(98) 00066-9

Sommer, S., Danysz, W., Russ, H., Valastro, B., Flik, G., and Hauber, W. (2014). The dopamine reuptake inhibitor MRZ-9547 increases progressive ratio responding in rats. Int. J. Neuropsychopharmacol. 17, 2045-2056. doi: $10.1017 / \mathrm{s} 1461145714000996$

Soto, P. L., Hiranita, T., Xu, M., Hursh, S. R., Grandy, D. K., and Katz, J. L. (2016). Dopamine D2-like receptors and behavioral economics of food reinforcement. Neuropsychopharmacology 41, 971-978. doi: 10.1038/npp. 2015.223

Stewart, W. J. (1974). Progressive reinforcement schedules: a review and evaluation. Aust. J. Psychol. 27, 9-22. doi: 10.1080/00049537508255235

Stotz, G., Woggon, B., and Angst, J. (1999). Psychostimulants in the therapy of treatment-resistant depression Review of the literature and findings from a retrospective study in 65 depressed patients. Dialogues Clin. Neurosci. 1, $165-174$.

Tadano, T., Nakagawasai, O., Niijima, F., Tan-No, K., and Kisara, K. (2000). The effects of traditional tonics on fatigue in mice differ from those of the antidepressant imipramine: a pharmacological and behavioral study. Am. J. Chin. Med. 28, 97-104. doi: 10.1142/s0192415x0000012x

Thompson, A. B., Gerson, J., Stolyarova, A., Bugarin, A., Hart, E. E., Jentsch, J. D., et al. (2017). Steep effort discounting of a preferred reward over a freely-available option in prolonged methamphetamine withdrawal in male rats. Psychopharmacology 234, 2697-2705. doi: 10.1007/s00213-0174656-z

Thorndike, E. L. (1911). Animal Intelligence. New York, NY: Macmillan.

Treadway, M. T., Bossaller, N. A., Shelton, R. C., and Zald, D. H. (2012a). Effort-based decision making in major depressive disorder: a translational model of motivational anhedonia. J. Abnorm. Psychol. 121, 553-558. doi: $10.1037 / \mathrm{a} 0028813$

Treadway, M. T., Buckholtz, J. W., Cowan, R. L., Woodward, N. D., Li, R., Ansari, M. S., et al. (2012b). Dopaminergic mechanisms of individual differences in human effort-based decision-making. J. Neurosci. 32, 6170-6176. doi: 10.1523/JNEUROSCI.6459-11.2012

Trifilieff, P., Feng, B., Urizar, E., Winiger, V., Ward, R. D., Taylor, K. M., et al. (2013). Increasing dopamine D2 receptor expression in the adult nucleus accumbens enhances motivation. Mol. Psychiatry 18, 1025-1033. doi: $10.1038 / \mathrm{mp} .2013 .57$

Tylee, A., Gastpar, M., Lépine, J. P., and Mendlewicz, J. (1999). DEPRES II (Depression Research in European Society II): a patient survey of the symptoms, disability and current management of depression in the community. Int. Clin. Psychopharmacol. 14, 139-151. doi: 10.1097/00004850199905030-00001

van den Bos, R., van der Harst, J., Jonkman, S., Schilders, M., and Spruijt, B. (2006). Rats assess costs and benefits according to an internal standard. Behav. Brain Res. 171, 350-354. doi: 10.1016/j.bbr.2006.03.035
Varazzani, C., San-Galli, A., Gilardeau, S., and Bouret, S. (2015). Noradrenaline and dopamine neurons in the reward/effort trade-off: a direct electrophysiological comparison in behaving monkeys. J. Neurosci. 35, 7866-7877. doi: 10.1523/JNEUROSCI.0454-15.2015

Vassena, E., Deraeve, J., and Alexander, W. H. (2017). Predicting motivation: computational models of PFC can explain neural coding of motivation and effort-based decision-making in health and disease. J. Cogn. Neurosci. 29, 1633-1645. doi: 10.1162/jocn_a_01160

Venugopalan, V. V., Casey, K. F., O’Hara, C., O'Loughlin, J., Benkelfat, C., Fellows, L. K., et al. (2011). Acute phenylalanine/tyrosine depletion reduces motivation to smoke cigarettes across stages of addiction. Neuropsychopharmacology 36, 2469-2476. doi: 10.1038/npp. 2011.135

Vezina, P., Lorrain, D. S., Arnold, G. M., Austin, J. D., and Suto, N. (2002). Sensitization of midbrain dopamine neuron reactivity promotes the pursuit of amphetamine. J. Neurosci. 22, 4654-4662.

Volkow, N. D., Chang, L., Wang, G. J., Fowler, J. S., Leonido-Yee, M., Franceschi, D., et al. (2001). Association of dopamine transporter reduction with psychomotor impairment in methamphetamine abusers. Am. J. Psychiatry 158, 377-382. doi: 10.1176/appi.ajp.158.3.377

Wakabayashi, K. T., Fields, H. L., and Nicola, S. M. (2004). Dissociation of the role of nucleus accumbens dopamine in responding to reward-predictive cues and waiting for reward. Behav. Brain Res. 154, 19-30. doi: 10.1016/j.bbr. 2004.01.013

Walton, M. E., Bannerman, D. M., Alterescu, K., and Rushworth, M. F. S. (2003). Functional specialization within medial frontal cortex of the anterior cingulated for evaluating effort-related decisions. J. Neurosci. 23, 6475-6479.

Walton, M. E., Bannerman, D. M., and Rushworth, M. F. (2002). The role of rat medial frontal cortex in effort-based decision making. J. Neurosci. 22, 10996-11003.

Walton, M. E., Kennerley, S. W., Bannerman, D. M., Phillips, P. E., and Rushworth, M. F. (2006). Weighing up the benefits of work: behavioral and neural analyses of effort-related decision making. Neural Netw. 19, 1302-1314. doi: 10.1016/j.neunet.2006.03.005

Wang, H., Chen, X., Li, Y., Tang, T. S., and Bezprozvanny, I. (2010). Tetrabenazine is neuroprotective in Huntington's disease mice. Mol. Neurodegener. 5:18. doi: 10.1186/1750-1326-5-18

Wardle, M. C., Treadway, M. T., Mayo, L. M., Zald, D. H., and de Wit, H. (2011). Amping up effort: effects of d-amphetamine on human effort-based decisionmaking. J. Neurosci. 31, 16597-16602. doi: 10.1523/JNEUROSCI.4387-11.2011

Wassum, K. M., and Izquierdo, A. (2015). The basolateral amygdala in reward learning and addiction. Neurosci. Biobehav. Rev. 57, 271-283. doi: 10.1016/j. neubiorev.2015.08.017

Winstanley, C. A., and Floresco, S. B. (2016). Deciphering decision making: variation in animal models of effort- and uncertainty-based choice reveals distinct neural circuitries underlying core cognitive processes. J. Neurosci. 36, 12069-12079. doi: 10.1523/JNEUROSCI.1713-16.2016

Wood, J., Simon, N. W., Koerner, F. S., Kass, R. E., and Moghaddam, B. (2017). Networks of VTA neurons encode real-time information about uncertain numbers of actions executed to earn a reward. Front. Behav. Neurosci. 11:140. doi: $10.1101 / 084970$

Woolverton, W. L., and Ranaldi, R. (2002). Comparison of the reinforcing efficacy of two dopamine D2-like receptor agonists in rhesus monkeys using a progressive-ratio schedule of reinforcement. Pharmacol. Biochem. Behav. 72, 803-809. doi: 10.1016/s0091-3057(02)00749-9

Worden, L. T., Shahriari, M., Farrar, A. M., Sink, K. S., Hockemeyer, J., Müller, C., et al. (2009). The adenosine $A_{2 A}$ antagonist MSX-3 reverses the effort-related effects of dopamine blockade: differential interaction with $\mathrm{D}_{1}$ and $\mathrm{D}_{2}$ family antagonists. Psychopharmacology 203, 489-499. doi: 10.1007/s00213-0081396-0

Yang, X. H., Huang, J., Lan, Y., Zhu, C. Y., Liu, X. Q., Wang, Y. F., et al. (2016). Diminished caudate and superior temporal gyrus responses to effort-based decision making in patients with first-episode major depressive disorder. Prog. Neuropsychopharmacol. Biol. Psychiatry 64, 52-59. doi: 10.1016/j.pnpbp.2015. 07.006

Yang, X. H., Huang, J., Zhu, C. Y., Wang, Y. F., Cheung, E. F., Chan, R. C., et al. (2014). Motivational deficits in effort-based decision making in individuals with subsyndromal depression, first-episode and remitted 
depression patients. Psychiatry Res. 220, 874-882. doi: 10.1016/j.psychres.2014. 08.056

Yohn, S. E., Alberati, D., Correa, M., and Salamone, J. D. (2017a). Assessment of a glycine uptake inhibitor in animal models of effort-related choice behavior: implications for motivational dysfunctions. Psychopharmacology 234, 1525-1534. doi: 10.1007/s00213-016-4523-3

Yohn, S. E., Gorka, D., Mistry, A., Collins, S., Qian, E., Correa, M., et al. (2017b). Oral ingestion and intraventricular injection of curcumin attenuates the effort-related effects of the VMAT-2 inhibitor tetrabenazine: implications for motivational symptoms of depression. J. Nat. Prod. 80, 2839-2844. doi: 10.1021/acs.jnatprod.7b00425

Yohn, S. E., Arif, Y., Haley, A., Tripodi, G., Baqi, Y., Müller, C. E., et al. (2016a). Effort-related motivational effects of the pro-inflammatory cytokine interleukin-6: pharmacological and neurochemical characterization. Psychopharmacology 233, 3575-3586. doi: 10.1007/s00213-016-4392-9

Yohn, S. E., Collins, S. L., Contreras-Mora, H. M., Errante, E. L., Rowland, M. A., Correa, M., et al. (2016b). Not all antidepressants are created equal: differential effects of monoamine uptake inhibitors on effort-related choice behavior. Neuropsychopharmacology 41, 686-694. doi: 10.1038/npp.2015.188

Yohn, S. E., Errante, E. L., Rosenbloom-Snow, A., Sommerville, M., Rowland, M. A., Tokarski, K., et al. (2016c). Blockade of uptake for dopamine, but not norepinephrine or 5-HT, increases selection of high effort instrumental activity: implications for treatment of effort-related motivational symptoms in psychopathology. Neuropharmacology 109, 270-280. doi: 10.1016/j. neuropharm.2016.06.018

Yohn, S. E., Gogoj, A., Haque, A., Lopez-Cruz, L., Haley, A., Huxley, P., et al. (2016d). Evaluation of the effort-related motivational effects of the novel dopamine uptake inhibitor PRX-14040. Pharmacol. Biochem. Behav. 148, 84-91. doi: 10.1016/j.pbb.2016.06.004
Yohn, S. E., Lopez-Cruz, L., Hutson, P. H., Correa, M., and Salamone, J. D. (2016e). Effects of lisdexamfetamine and s-citalopram, alone and in combination, on effort-related choice behavior in the rat. Psychopharmacology 233, 949-960. doi: 10.1007/s00213-015-4176-7

Yohn, S. E., Santerre, J. L., Nunes, E. J., Kozak, R., Podurgiel, S. J., Correa, M., et al. (2015a). The role of dopamine D1 receptor transmission in effort-related choice behavior: effects of D1 agonists. Pharmacol. Biochem. Behav. 135, 217-226. doi: 10.1016/j.pbb.2015.05.003

Yohn, S. E., Thompson, C., Randall, P. A., Lee, C. A., Müller, C. E., Baqi, Y., et al. (2015b). The VMAT-2 inhibitor tetrabenazine alters effort-related decision making as measured by the T-maze barrier choice task: reversal with the adenosine $\mathrm{A}_{2 \mathrm{~A}}$ antagonist MSX-3 and the catecholamine uptake blocker bupropion. Psychopharmacology 232, 1313-1323. doi: 10.1007/s00213-0143766-0

Zénon, A., Devesse, S., and Olivier, E. (2016). Dopamine manipulation affects response vigor independently of opportunity cost. J. Neurosci. 36, 9516-9525. doi: 10.1523/JNEUROSCI.4467-15.2016

Conflict of Interest Statement: The authors declare that the research was conducted in the absence of any commercial or financial relationships that could be construed as a potential conflict of interest.

Copyright (C) 2018 Salamone, Correa, Yang, Rotolo and Presby. This is an open-access article distributed under the terms of the Creative Commons Attribution License (CC BY). The use, distribution or reproduction in other forums is permitted, provided the original author(s) and the copyright owner are credited and that the original publication in this journal is cited, in accordance with accepted academic practice. No use, distribution or reproduction is permitted which does not comply with these terms. 